\title{
Assessment of Climate Comfort for Central Russia Residents
}

\author{
Katerina KULAGINA ${ }^{1}$ and Tatiana TRIFONOVA ${ }^{2}$ \\ ${ }^{1}$ Vladimir State University / Russia·kylaginaek@mail.ru \\ ${ }^{2}$ Lomonosov State University, Moscow / Russia
}

This contribution was double-blind reviewed as extended abstract.

\begin{abstract}
The human body is influenced by a complex of factors, including bioclimatic conditions. Biological climate of an area is an essential natural resource, whose condition influences human comfort, work efficiency, productivity and health. Comfortable weather refers to meteorological conditions when a person feels best. This project aims to define the integral bioclimatic comfort of the territory with the use of modern GIS-technologies.
\end{abstract}

\section{Introduction}

Residential conditions comfort is considered as the characteristics of the human environment, and is primarily assessed by its influence rate on human health. Basic components providing conditions comfort include natural, demographic, social and other indicators. Recently, great interest was sparked by the investigation of factors, characterizing human thermal conditions, defined mainly by local climatic conditions. The most widely spread method of thermal comfort assessment is the evaluation of local conditions based on climatic indices, represented by the combined impact of several meteorologic parameters (ARNOLDI 1962, AISENSCHTAT 1969, RUSANOV 1973/2004, GRIGORIEVA, 2004, LI, CHAN 2000, ZHANG 2006 and others). Bioclimatic parameters are connected with a human being and characterize the relation of climate and its thermal condition, health, recreation peculiarities and sanitary-hygienic assessment in the natural environment.

\section{Input Data and Data Processing}

The Central Federal district (CFD) of the RF, located in the central European part of Russia has been chosen as a research object. The district consists of 18 regions (entities). Initial data included statistics (period of 2001-2010) published by the Federal Agency of Hydrometeorology and Environment Monitoring, received from 44 meteorological stations of the CFD and bordering regions. The district area is $651700 \mathrm{~km}^{2}(3,8 \%$ of Total Russia area). 
In the first stage, parameters such as air temperature, wind speed, cloudiness, humidity, atmospheric pressure, day temperature and pressure change were calculated. Next, the following bioclimatic indices were computed by applying modern geoinformatonal systems (GIS): effective temperature - characterizing temperature and wind speed impact effect on a human being (STEDMAN 1994); equivalent-effective temperature - aggregating the impact of temperature, humidity and wind speed (RUSANOV 1981); biologically active temperature - defining the influence of temperature, humidity and wind speed on the human body (TSITSENKO 1971); climatic comfort quantitative criterion - combining the impact of temperature and wind speed (HILL 1981), and meteorological environment pathogenicity revealing the character of irritating weather impact on a human being (BOKSHA et al. 1980).

The enumerated indices include various combinations of meteoparameters with different unit measures and comfort scales with various numbers of classes. Thus, the analysis based on bioclimatic conditions descriptions for separate indices does not allow receiving unbiased information concerning the comfort conditions of the areas as a whole. In this connection we suggest to assess integral bioclimatic comfort regarded as an aggregation of climatic comfort characteristics, providing an optimal human body condition, when a functional tension of adaptation mechanisms does not emerge.

Bioclimatic index computing was performed by applying modern geoinformational systems (GIS), namely, ArcView. Every bioclimatic factor received a point evaluation by scaling indices values into 5 classes, each corresponding to a different comfort level - from uncomfortable to highly comfortable levels (see figure 1). Comfortable and uncomfortable value limits of every index were observed.

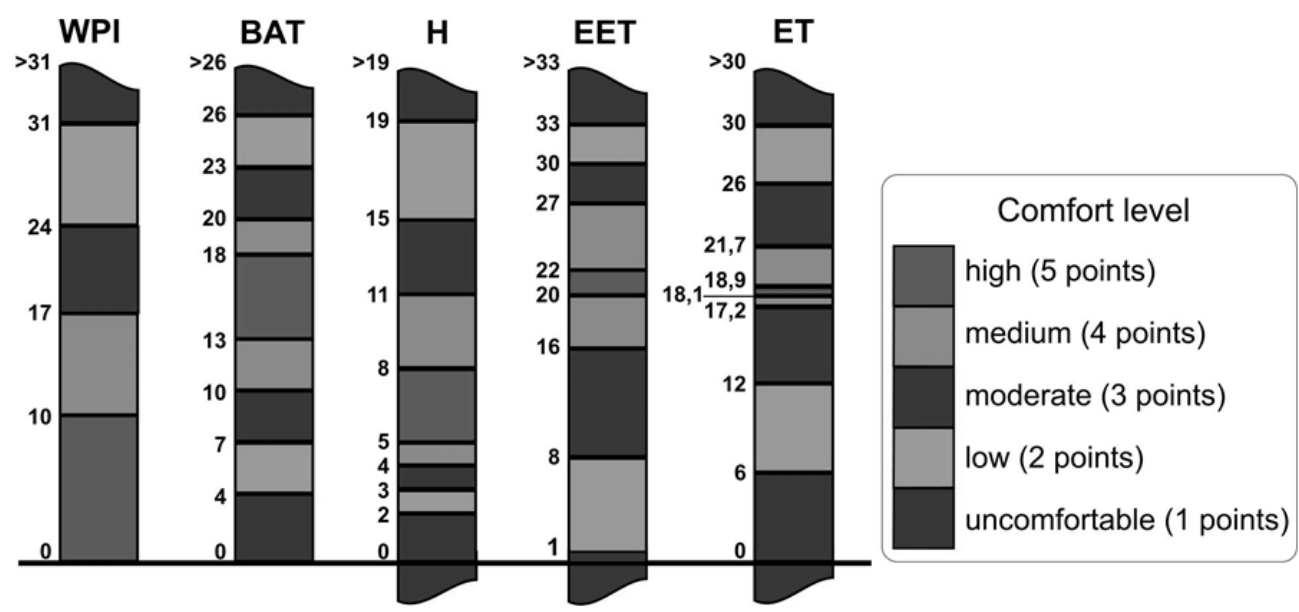

Fig. 1: Comfort level (WPI - weather pathogenicity index; BAT - biologically active temperature; $\mathrm{H}$ - climate comfort quantitative criterion; EET - equivalenteffective temperature; ET - effective temperature)

Furthermore, applying the GIS-package ArcGIS 9.3 with the additional Spatial Analyst module, reclassification, as well as bioclimatic layers summation and averaging were performed, resulting in integral bioclimatic comfort map compiling (see figure 2). 


\section{Results}

According to the received results, conditions are characterized by moderate comfort basically within the whole area. The regions possessing high comfort levels have not been revealed. The most favorable conditions are found in the Southern part of CFD $(2.2-2.4$ points), which differ in high values of biologically active temperature, making the greatest contribution in the level of integral bioclimatic comfort.

The regions located in this area with a dominating descend of landscape shape in the eastern part of the district (Vladimir, Ryazan, Tambov regions) are characterised by low conditions comfort $(1.5-2.0$ points). These regions are basically influenced by severe conditions regarding the weather pathogenicity index.

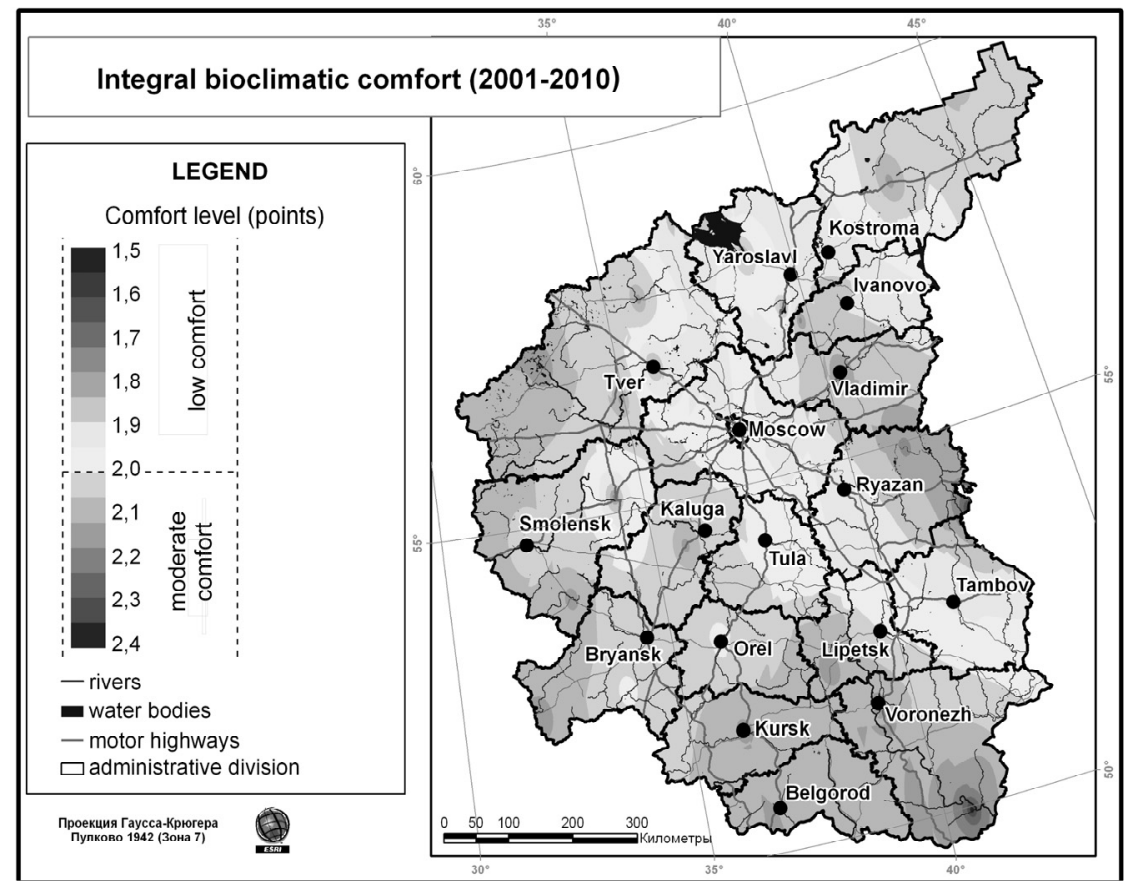

Fig. 2: Integral bioclimatic comfort (2001-2010)

\section{Conclusion and Outlook}

Thus we have suggested and developed a method for defining integral bioclimatic comfort of the area. The research results can be used as a scientifically proven basis in the choice of recreation areas, as well as for providing unbiased information concerning risk levels for population health, dependant on the impact of climatic factors complex. 


\section{References}

DMITRIEVA, V. T. \& NAPRASNIKOV. A. T., Geographic and climatic comfort factors of East Transbaikalia region. Geography - problems and development perspectives. MGPU Reportes. Natural Science, 15-25.

KALKSTEIN, L. S. (2001), Biometeorology - insight of weather, climate and health relation. World METEOROLOGICAL ORGANIZATION BULLETIN, 50, 1-6.

Vinogradova, V. V. (2009), Bioclimatic indices in assessing the impact of climate warming on the modern conditions of life in Russia. Izvestia Akad. Nauk, Seria Geogr., $3,82-89$. 